Casuarius papuanus 2 Stück, von mir, " Bennetti 1 Stück, also alle bekannten Arten in zusammen 20 Exemplaren.

Darmstadt, den 31. März 1873.

Baron Rosenberg.

\title{
Berichtigung zu dem Artikel \\ g,das Reichsmuseum in Leyden von F. Freiherrn v. Droste ${ }^{66}$.
} "Suum cuique!"

In. dem 5. Hefte des Journals für Ornithologie, Jahrg. 1867, findet sich auf Seite 3õ2-355 der obigen Titel führende Aufsatz, welcher mir erst vor Kurzem unter die Augen kam. Es finden sich darin viele Unrichtigkeiten und schiefe Vorstellungen, die ich in den folgenden Zeilen nachweisen und auf ihr richtiges Maass zurückführen will.

H. v. D. sagt darin: „46 Paradisea apoda, 21 rubra, sämmtlich von Bernstein gesammelt". Dass dies letztere nicht der Fall ist, davon hätte H. v. D. sich leicht überzeugen können, wenn er einen besseren Gebrauch von seinen Augen gemacht hätte. Er würde dann auf 44 Etiquetten von Paradisea apoda meinen Namen und nicht den von Bernstein gelesen haben.

Mehrere Zeilen weiter spricht H. v. D. von Professor Schlegel's Studien über Oertlichkeit und Sitten und Gebräuche der Eingeborenen zum Nutzen jeder neuzuorganisirenden Reise. Woher hat H. v. D. diese Mittheilung? Gewiss nicht in dieser Weise aus dem Munde meines hochverehrten Freundes, des Herrn Schlegel. Solche Studien waren ja überflüssig bei den drei Reisenden (Hoedt, Bernstein und Unterzeichnetem), die während der letzten Decennien in Indien für Leyden gesammelt haben. Hoedt, auf Amboina geboren, war indischer Regierungsbeamter und mit der Oertlichkeit und den Sitten und Gebräuchen der Einwohner der Inseln binlänglich bekannt, welche er später bereiste. Bernstein, Privatier und nur zeitlich, ohne irgend einen Rang zu bekleiden, durch die indische Regierung employirt, war schon 5 Jahre in Indien, als er den Auftrag bekam, für das Leydener Museum zu sammeln. Ich selbst befand mich schon 23 Jahre in indischen Diensten, hatte Sumatra, Java, die Molukken gesehen, war territorialer Regierungschef gewesen, als mir vom Gouvernement der gleiche Auftrag ertheilt wurde. Professor Schlegel hatte also wahrlich nicht nöthig, uns den Inhalt seiner Studien mitzutheilen über Land und Volk, was 
wir weit gründlicher käinteh, wie ef šelbst. Mir zum mindesten hat er nichts darüber mitgetheilt.

Weiter heisst es: „\$o kohnten Conflicte mit den Eingebórenen vermieden werden und war der Réeisende tobl unterrichtet von Allem". Wenn H. v: D. jemals unter sogenannten Wilden gereist hätte, würde er diese Worte, von welchen ich voraussetze, dass dieselben so nicht dús Schletgel's Mühde gagdingên sind, schwerlich hiełtergèschrieben haben. Denn dass es selbst bei der genturesten Bekanntschaft mit Charakter und Gebräuchen der Eingeborenen dennoch möglich ist, ndit 'denselben in Cơnflict z't gerathen; weiss ich aus eigener Erfahtrung: Auch Bèrnstein; der freilich Küchenmalayiséh sprach und mit den Eingeborëneh ebensowenity umgetheh könnte wie mit Europżern; könthté, wenn 'ér nbch lebte; 'ëin Gleiches mittheilei. Und was die Flosicel ;; whohl unterrichtet von Allent" betrifft, so ist dies eben nur eine - Floskel, dèren Tragwèitè $\mathrm{H}$. v. D. nicht gechörig in's Auge gefàsst hat und die gewís nicht aus Schlegel's Mund gekommen ist. Ich; der ich 15 Jáhre langt die Westküste von Sumatrà bereist habe und diestlbe besserer kenne wie mein Geburtsland Héssen; hüte inich woht; bezüglich jeftes herrlichen Gebiets einen soldehen Ausspruch zu thuni:

Endlich sagt H. v. D: noch: ,żum Acclimatisiren lässt èr (Schlegel) den Rélsenden zuerst èille gesunde Insel unitërsulchen". Ich möchte wohl wisseh, mit welchent Reisenden dies geschehén ist; wir Drei, naimentlich Hoedt und ich, bedurften doch wahrlich keiner Acclimatisation mehr, als wir unser Manddat empfingèh. Uñd was meint H. v. D. (immer von dem Standpunkte ausgehiend; daiss Schlegel sich unmöglich in solcher Weise geatussert haben kanin), mit "gesunder Iusel“ und wo liegt dieselbe? Dië grossen Itšèln des Archipels haben Gegendett; die gesund, und andered, die thgesurild siñd, und kann man desllalb von keiner sägen, sie šbi ulibédingt das eind oder das andere. Unter den kleineren Inseln giebt es dagegen wohl manclie, die als gesúnd bekannt sint, wie $z$. $\mathbf{B}$. Amboina tind Ternate; darum bleibt aber doch der neuangekommedte Europäer ebensosehr den Wirküngen dér tropischen Sonnè auch da blossigestellt.

Mit meinen Berichtigungen zu Ende, schreite ich tuim Schluss. Nach H. ₹. D. Vorstelling sollte man glauben, wir Wären nichits Anderes gewesen als Drahtpuppen in der Hand des MuseumisDirectors in Leyden. Nichts ist jedoch tunrichtiger wie diése Meinung, zum mińdesten was mich betrat. 
Dr. O. Fins ch: Ueber Clitohyx Reichib: Ư. Phyllodytes Finsch. 393

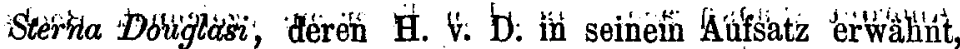

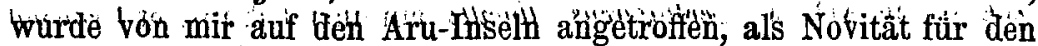
indischen Arctipel.

Im Besitze einer kleinen Sammlung ausgestopfter Vögel, wơrunter thanchies Seltène, lade ich die Herren Ornithologen auf ihrer Durchieise durch Darmśntádt zur Bèsichtigung heiner Schätże freundlichsist ein.

Darmstadt, den 1: April 1873.

$$
\begin{gathered}
\text { Jeber die Systematische Stellung } \\
\text { Baron Rösën berg. } \\
\text { der nenseeländischen Gattungen Clitonyx Reiehb. unid } \\
\text { Phytlodytes Finseh. } \\
\text { Dr. Otto Finsch in Brëmen. }
\end{gathered}
$$

Ich habe in meinen bisherigen Arbeitè aber neuseländišche Ornis, dem Vorgange G. R. Grày's (Ibis 1862, p. 220) folgendà, die "Frïrgilla álbicilla Lessón (voy. Coqü. Zool. I. p. 66z) dém Geilus Orthony $x$ Tetith. eingereitht, sprach aber schon in der Ucbersetzuing zu Buller's "Essay di the Ornith. of N. Z." dic Verriuuthung aus (Journ. f. Orn. 1867, p. 320; Note), dass die genannte Art wobl mèhr zuith Gétus Cèrthiparis Lafr. gehören werdè. Dir. Builer, dër mine Uebèrsetżung seinès „Essay̆“ zum Gegenstảnd eibler klèinen Abhandlung mäclite, sagt in dersélben (Trans. èt Proced. of the N. Z. Inst. I. 1869; p. 108, 10): „Es würde ohne alle Frage falsch sein, dié beiden Papokatea-Ärten, Moloía albicilla und $M$. ochrocephala in der Wëisé (wie ich diès vorgeschlagen), gèierisch zu trétinen, da sie ganz nahe verwaridt sind. In der Gestalt ähneln sie einander, obschoon sie verschieden gêfärbt sild, und ihre Leben'stweise ist génau dicsélbe. Sie rephräsentirën eindinUer auf der Nord- und Südinsel", und wiederholt diese Àrisichten in seinem Aufsatze ;Further Notes on the Ornitli. of N.Z." (Trans. et Proc. N: Z. Inst. vol. III. 1871. Trans. p. 40); so wie in seinem grossen Werke (Hist. B. of N. Z. p. 10i). Atuch mir blieb nichts übrig, als thich diesem Urtheile anzuschliéssen (Journ. f. Orn. 1870, p. 253, und 1872, p. 110), da mir die Fringilla álbicilla Less, eben ittir nách dèr Abbildung Gray's (vòy. Ereb. et T'err. t. 5. f. 2) bekkañnt wat, welche bëzugglich der generischen Charaktïre (Fuss- oder Flügelbildúng) keive nähèren Details àngiebt; um so webr; als sich auch Potts ébenfalls zu Gunstè der Buller'schen 